\author{
Maurizio Cecconi \\ Christoph Hofer \\ Jean-Louis Teboul \\ Ville Pettila \\ Erika Wilkman \\ Zsolt Molnar \\ Giorgio Della Rocca \\ Cesar Aldecoa \\ Antonio Artigas \\ Sameer Jog \\ Michael Sander \\ Claudia Spies \\ Jean-Yves Lefrant \\ Daniel De Backer \\ on behalf of the FENICE Investigators \\ and the ESICM Trial Group
}

\section{Fluid challenges in intensive care: the FENICE study}

\author{
A global inception cohort study
}

Received: 16 March 2015

Accepted: 27 April 2015

Published online: 11 July 2015

(C) The Author(s) 2015. This article is

published with open access at

Springerlink.com

Electronic supplementary material

The online version of this article (doi:10.1007/s00134-015-3850-x) contains supplementary material, which is available to authorized users.

The FENICE investigators are listed in full in ESM 2 (National Coordinators) and ESM 4 (Steering Committee, Study Statistician, Study Coordinator and Local Investigators).

Trial registration: ClinicalTrials.Gov NCT01787071.

M. Cecconi $(\varangle) \cdot$ on behalf of the FENICE Investigators and the ESICM Trial Group Anaesthesia and Intensive Care, St George's Hospital and Medical School, London SW17 0QT, UK

e-mail: mcecconi@sgul.ac.uk

Tel.: 00442087253295

\section{Hofer}

Institute of Anaesthesiology and Intensive Care Medicine, Triemli City Hospital
Zurich, Birmensdorferstrasse 497, 8063

Zurich, Switzerland

\section{J.-L. Teboul}

Hôpitaux universitaires Paris-Sud, Hôpital de Bicêtre, Service de réanimation

médicale, 78, rue du Général Leclerc, 94270

Le Kremlin-Bicêtre, France

J.-L. Teboul

Faculté de médecine Paris-Sud, EA4533, University Paris-Sud, 63, rue Gabriel Péri, 94270 Le Kremlin-Bicêtre, France

V. Pettila $\cdot$ E. Wilkman

Intensive Care Units, Department of Anesthesiology, Intensive Care Medicine and Pain Medicine, Helsinki University Hospital, Helsinki, Finland

\section{Z. Molnar}

Department of Anaesthesiology and

Intensive Therapy, University of Szeged,

Szeged, Hungary

\section{G. Della Rocca}

Department of Anesthesia and Intensive Care Medicine, University Hospital,

Medical School, University of Udine, P.le S. Maria della Misericordia, 33100 Udine, Italy

\section{Aldecoa}

Department of Anesthesiology and Surgical Critical Care, Hospital Universitario Rio Hortega, Valladolid, Spain
A. Artigas

Critical Care Center, CIBER Enfermedades Respiratorias, Sabadell Hospital, Corporació Sanitaria Universitaria Parc Tauli, Autonomous University of Barcelona, Barcelona, Spain

\section{S. Jog}

Deenanath Mangeshkar Hospital and Research Center, Pune 411004, India

M. Sander · C. Spies

Department of Anesthesiology and Intensive Care Medicine, Charité University Medicine Berlin, Charité Campus Mitte, Campus Virchow Klinikum, Charitéplatz 1, 10117 Berlin, Germany

\section{J.-Y. Lefrant}

Service des Réanimations, CHU Nîmes, Place du Professeur Robert Debré, 30029

Nîmes cedex 9, France

\section{De Backer}

Department of Intensive Care, Erasme University Hospital, Université Libre de Bruxelles, Brussels, Belgium

\section{De Backer}

Department of Intensive Care, CHIREC Hospitals, Brussels, Belgium

\section{Abstract Background: Fluid} challenges (FCs) are one of the most commonly used therapies in critically ill patients and represent the cornerstone of hemodynamic management 
in intensive care units. There are clear benefits and harms from fluid therapy. Limited data on the indication, type, amount and rate of an FC in critically ill patients exist in the literature. The primary aim was to evaluate how physicians conduct FCs in terms of type, volume, and rate of given fluid; the secondary aim was to evaluate variables used to trigger an FC and to compare the proportion of patients receiving further fluid administration based on the response to the FC.

Methods: This was an observational study conducted in ICUs around the world. Each participating unit entered a maximum of 20 patients with one
FC. Results: 2213 patients were enrolled and analyzed in the study. The median [interquartile range] amount of fluid given during an FC was $500 \mathrm{ml}$ (500-1000). The median time was $24 \mathrm{~min}$ (40-60 $\mathrm{min}$ ), and the median rate of FC was 1000 [500-1333] $\mathrm{ml} / \mathrm{h}$. The main indication for FC was hypotension in 1211 (59\%, CI 57-61\%). In $43 \%$ (CI $41-45 \%)$ of the cases no hemodynamic variable was used. Static markers of preload were used in 785 of 2213 cases (36\%, CI 34-37\%). Dynamic indices of preload responsiveness were used in 483 of 2213 cases $(22 \%$, CI $20-24 \%)$. No safety variable for the $\mathrm{FC}$ was used in $72 \%$ (CI 70-74\%) of the cases. There was no statistically significant difference in the proportion of patients who received further fluids after the FC between those with a positive, with an uncertain or with a negatively judged response. Conclusions: The current practice and evaluation of FC in critically ill patients are highly variable. Prediction of fluid responsiveness is not used routinely, safety limits are rarely used, and information from previous failed FCs is not always taken into account.

\section{Introduction}

Many liters of intravenous fluids are used per year to treat critically ill patients worldwide. Fluids are one of the most commonly used therapies in critically ill patients and represent the cornerstone of hemodynamic management in intensive care units (ICUs) [1]. The basic physiological target of administration of fluids is to improve tissue perfusion. Hemodynamic optimization with fluids has been shown to improve patient outcome when applied in the perioperative period and in the early phases of sepsis [1-4]. Timing of the intervention is important; in the context of shock, higher fluid administration in the first $3 \mathrm{~h}$ was associated with better outcome in a retrospective study [5]. On the other hand, liberal administration of fluids may lead to a positive fluid balance [6] which is independently associated with a poor outcome [7]. Accordingly, in patients with respiratory failure, once hemodynamically stable, fluid restriction is associated with earlier weaning from mechanical ventilation [8].

Altogether, it seems reasonable to give the needed amount of fluids when hemodynamically patients are unstable and to restrict fluids when they are stabilized. Such an approach makes physiological sense and in theory should bring better outcomes to the patients. Whereas in overt bleeding, fluids are often given without guidance with specific hemodynamic monitoring, in other conditions, when hypovolemia may be subtler or when the response to fluids is more variable, fluids may be given on the basis of monitoring their hemodynamic impact. This practice, the "fluid challenge" technique (FC) was proposed more than 30 years ago [9-11]. Over recent decades new techniques have been developed in order to monitor and predict the response to fluids. The roles of static markers of preload such as central venous pressure (CVP) and pulmonary artery occlusion pressure (PAOP) have been questioned and dynamic indices of preload have been studied [12-14]. The use of dynamic indices is now recommended [4] but many technical limitations may preclude their use.

However, no data exist on the manner in which FCs are indicated and performed in critically ill patients around the globe. We conducted a multicenter international observational study aiming to evaluate the indications, current practice, and judgment of benefit of FCs in critical care settings. We hypothesized that there is an extensive variation in the current practice of FC.

\section{Methods}

This was an observational study conducted by the ESICM Trials Group (17-23 April 2013 or 23-29 May 2013) and registered on ClinicalTrials.Gov (NCT01787071). ICUs were able to enter the study in one of the 2 weeks. The possibility to choose between 2 weeks was chosen in order to compensate for differences in national holidays in different countries and therefore to maximize the recruitment of study units. IRB approval was obtained in each country and the local investigators were responsible to ensure that with local and national requirements were fulfilled. In most participating countries informed consent from the patient was waived owing to the observational study design. National coordinators and local investigators are listed in the electronic supplementary material (ESM).

We included all consecutive adult (18 years old and above) patients, up to a maximum of 20 per participating unit, in whom an FC was performed during a 1-week period. FC was defined as administration of any bolus of fluid (crystalloid or colloid) in less than $2 \mathrm{~h}$. Administration of red blood cells or fresh frozen plasma was not considered as 
an FC. The exclusion criteria were previous inclusion in the study, overt bleeding, and time of an FC exceeding 120 min. Only one FC, ideally the first, was considered for each patient. Only one FC per patient was recorded.

We collected data on patient demographics, indications for the FC, the type, amount, and rate of fluids administered, available hemodynamic variables, and judgment on the efficacy and safety of the FC. The case report form (CRF) is available in the ESM. Anonymous CRF data were uploaded by local investigators using a Web-based electronic CRF (Clinfile, Sevres, France). The data were stored securely in a server located in Brussels. All procedures regarding data management complied with the EU directive on data protection $(95 / 46 / \mathrm{EC})$.

\section{Study aims}

The primary aim of this study was to evaluate how physicians indicate FC.

The secondary aims were

- to evaluate the type, volume, and rate of fluid administered during an FC.

- to evaluate variables used to trigger/indicate an FC, and to judge the effect or safety of an FC.

- to compare the proportion of patients receiving further fluid administration based on the response to the fluid challenge, as judged by the bedside clinician after a fluid challenge.

\section{Statistical analysis}

Categorical variables are described as numbers (percentages) and continuous variables as mean ( \pm standard deviation), if normally distributed, or median [interquartile range] if not normally distributed. The paired $t$ test or Wilcoxon test was used to compare hemodynamic variables after the FC with baseline, when applicable. Proportions of patients were compared with $\chi^{2}$ test and data presented as proportions and odd ratios. A $p$ value of less than 0.05 was considered statistically significant. We targeted a minimum of 100 study sites with a maximum of $20 \mathrm{FCs}$ each and a minimum of 1000 patients.

\section{Results}

We included 2279 patients with an FC from 311 centers across 46 countries (ESM). Of those 2279, 66 patients were excluded from the analysis as a result of at least one exclusion criterion (see the study flow chart, Fig. 1 ESM). A total of 2213 patients were analyzed.
Data on demographic factors and concomitant treatment are presented in Table 1 . The main diagnostic groups were sepsis $(n=595,27.0 \%$ [CI 25.2-28.9\%]), cardiac $(n=454,20.6 \%$ [CI 18.9-22.3\%]), and respiratory failure $(n=238,10.8 \%$ [CI 9.5-12.1\%]).

The median amount of fluid given during an FC was $500 \mathrm{ml}$ [500-1000]. The median time was $24 \mathrm{~min}$ [40-60 min], and the median rate of fluid administration was 1000 [500-1333] ml/h. Crystalloids were the most used (in 74.0\% [CI 72.2-75.8\%] of the cases) including normal saline in $45.9 \%$ [CI 25.2-28.9\%], and balanced solutions were used in $53.5 \%$ [CI 51.4-55.6\%] of FCs (Table 2).

The main indication for fluid administration was hypotension in 1211 (58.7 \% [CI 56.7-60.1\%]) of FCs. In $42.7 \%$ [CI 40.6-44.8\%] of the cases no hemodynamic variable was used to predict fluid responsiveness. Static markers of preload were used in 785 of 2213 cases (35.5\% [CI 33.5-37.5\%]). In 572 of 785 of these cases (89.9\% [CI 87.8-92.0\%]) CVP was the leading variable used (25.8\% [CI 24.0-27.6\%] of all FCs). Dynamic indices of preload responsiveness were used in 483 of 2213 cases (21.9\% [CI 20.2-23.6\%]). In 238 of those 483 cases $(49.3 \%$ [CI $44.8-53.8 \%$ ]) passive leg raising (PLR) was the leading variable (10.7\% [CI 9.4-12.0\%] of all FCs) (Table 3).

The response to fluid administration was judged as positive in 1544 of 2213 (69.8\% [CI 67.9-71.7\%]) of the FCs, most often as an increase in arterial blood pressure (1039 of 1544, $67.3 \%$ [CI 65.0-69.7\%]). No safety variable for the FC was used in $72.0 \%$ [CI 70.1-73.9\%] of the cases. When used, CVP was the most common variable $(57 \%)$. Further fluids were administered in 1050 of 2213 (49.8\% [CI 47.7-51.9\%]) of the cases. The proportion of patients who received further fluids after was similar in patients with a positive $(47.9 \pm 2.5 \%)$, with an uncertain $[52.4 \pm 7.1 \%$, OR $0.94(0.76-1.16)]$ or with a negatively judged response to FC $[49.4 \pm 6.6 \%$, OR $0.83(0.62-1.13)]\left(p=0.46\right.$ by $\chi^{2}$ test) (Fig. 1).

\section{Discussion}

The two major findings of this large global multicenter observational study comprising 2213 patients are first a significant variability in the conduction of FC and second the fact that the response to the initial FC does not have an impact when prescribing further fluid administration. These findings were observed in critically ill patients all around the world. All aspects of the FC, the type, volume, and rate of given fluids, and more importantly the indication, evaluation of possible benefit, and safety variables used varied significantly. It is possible that some of the 
Table 1 Baseline characteristics and concomitant treatments in critically ill patients $(N=2213)$

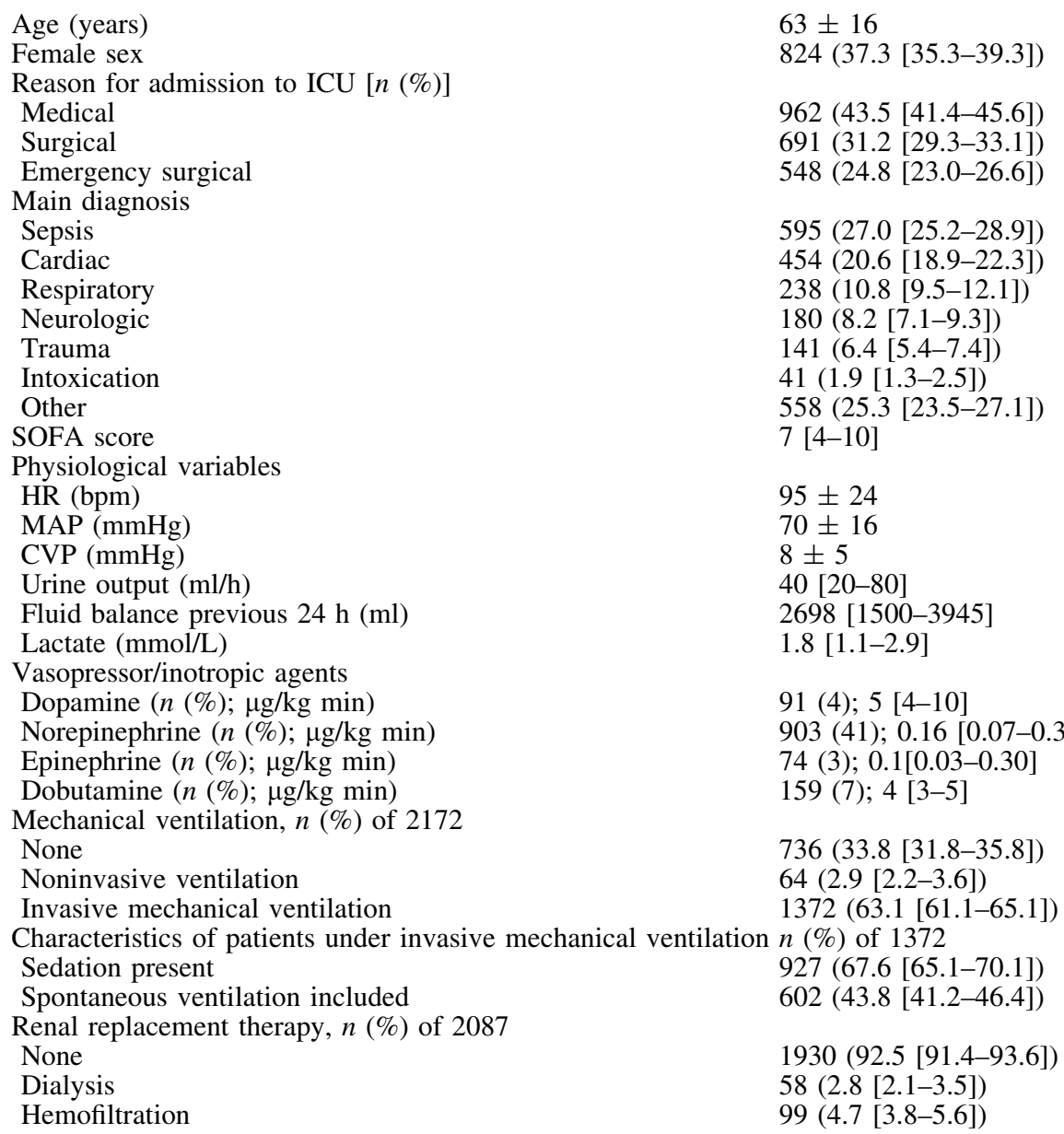

Qualitative data are given as absolute number (percentage); quantitative data are given as median value [interquartile range]

$H R$ heart rate, MAP mean arterial pressure, $C V P$ central venous pressure, $C V V H$ continuous venovenous hemofiltration

variability may be explained by variables not collected in our study, such as unit policies and protocols.

While we recorded only one FC per patient, we also recorded the decision for further fluid administration post FC. When looking at the response to fluid administration, investigators found a positive response only in seven cases out of ten. However, further fluids were given in comparable proportions of patients despite the initial response. If an FC is used to look at a dynamic response and to decide whether further fluids may be administered safely, one would expect that further fluids should be administered only in patients with a positive initial response. In our study the response to the initial fluid challenge made no difference to the decision for further fluid administration. This behavior seems to be harmful and highlights a huge need for education.

This huge variability in the current practice regarding an FC may reflect the presence of controversies in current guidelines. In the Surviving Sepsis Guidelines fluids are recommended in the very early phase of hemodynamic resuscitation of patients with severe sepsis [15]. In this case a fluid bolus is considered as administration of fluids of $30 \mathrm{ml} / \mathrm{kg}$. In high-risk surgical patients fluid challenges are often given in smaller amounts [11]. In the perioperative setting there are guidelines covering the administration of fluids recommending the use of fluids for stroke volume optimization [16]. While it is true that different conditions may require different techniques, our data show extensive variability even within the same clinical condition.

Simple clinical signs led to FC in more than $80 \%$ patients (hypotension, $58.7 \%$; oliguria, $18 \%$; or weaning of vasopressors, $7.1 \%$ ). Of note, markers of inadequate tissue perfusion such as lactate or skin mottling were used as an indication for an FC only in less than $8 \%$ of the cases. This seems paradoxical since fluids are mostly indicated to increase cardiac output $[11,17,18]$ and tissue perfusion [19]. Moreover, some studies focused on microcirculation clearly showed that clinical signs cannot predict microcirculatory 
Table 2 Fluid challenge $(N=2213)$ characteristics

\begin{tabular}{|c|c|c|c|}
\hline $\begin{array}{l}\text { Volume }(\mathrm{ml}) \text {, median }[\mathrm{IQR}] \\
\text { Rate }(\mathrm{ml} / \mathrm{h}) \text {, median [IQR] } \\
\text { Type of fluids }\end{array}$ & $\begin{array}{l}500[500-999] \\
1000[500-1333] \\
n\end{array}$ & $\%$ Of category & $\%$ All fluids \\
\hline Crystalloids & 1713 & & $74.3[72.5-76.1]$ \\
\hline $\mathrm{NaCl} 0.9 \%$ & 786 & 45.9 [43.5-48.3] & 34.1 [32.1-36.1] \\
\hline Balanced & 916 & $53.5[51.1-55.9]$ & $39.8[37.8-41.8]$ \\
\hline G5 \% DW & 4 & $0.2[0.0-0.4]$ & $0.2[0.0-0.4]$ \\
\hline G5 \% NaCl $0.45 \%$ & 7 & $0.4[0.1-0.7]$ & $0.3[0.1-0.5]$ \\
\hline Colloids & 591 & & $25.6[23.8-27.4]$ \\
\hline HES & 249 & $42.1[38.1-46.1]$ & $10.8[9.5-12.1]$ \\
\hline Albumin $4-5 \%$ & 101 & $17.1[14.1-20.1]$ & $4.3[3.5-5.2]$ \\
\hline Gelatin & 203 & $34.3[30.5-38.1]$ & $8.8[7.6-10.0]$ \\
\hline Dextran & 13 & $2.2[1.0-3.4]$ & $0.5[0.2-0.8]$ \\
\hline Albumin $20 \%$ & 25 & $4.2[2.6-5.8]$ & $1.1[0.7-1.5]$ \\
\hline
\end{tabular}

$\mathrm{NaCl}$ saline, balanced crystalloids with chloride concentration lower than saline (i.e., Plasma Lyte, Hartman's), G5 \% glucose $5 \%, \mathrm{DW}$ dextrose in water, HES hydroxyethyl starch

Table 3 Indications and variables used to predict fluid responsiveness $(N=2213)$

\begin{tabular}{|c|c|c|c|}
\hline \multicolumn{2}{|l|}{ Indication } & \multicolumn{2}{|r|}{$n(\%)$} \\
\hline Hypotension & & & $1211(58.7[56.7-60.8])$ \\
\hline Weaning vasopressor & & & $146(7.1[6.0-8.2])$ \\
\hline Cardiac output & & & $62(3.0)[2.3-3.7]$ \\
\hline Oliguria & & & $372(18.0[16.4-19.6])$ \\
\hline Skin mottling & & & $36(1.7[1.2-2.2])$ \\
\hline Lactate & & & $128(6.2[5.2-7.2])$ \\
\hline $\mathrm{SvO}_{2} / \mathrm{ScvO}_{2}$ & & & $10(0.5[0.2-0.8])$ \\
\hline SVV/PPV & & & 37 (1.8 [1.3-2.4]) \\
\hline CVP/PAOP & & & $60(2.9[2.2-3.6])$ \\
\hline Hemodynamic variable used to predict fluid responsiveness & $n$ & $\%$ Of category & $\%$ All \\
\hline No variable used & 945 & & $42.7[40.6-44.8]$ \\
\hline Any variable used & 1268 & & $57.3[55.2-59.4]$ \\
\hline Static & 785 & & $35.5[33.5-37.5]$ \\
\hline CVP & 572 & 89.9 [87.8-92.0] & $25.8[24.0-27.6]$ \\
\hline PAOP & 31 & $4.9[3.4-6.4]$ & $1.4[0.9-1.9]$ \\
\hline GEDVI & 33 & $5.2[3.6-6.8]$ & $1.5[1.0-2.0]$ \\
\hline Other & 149 & $23.4[20.4-26.4]$ & $6.7[5.7-7.8]$ \\
\hline Dynamic & 483 & & $21.9[20.2-23.6]$ \\
\hline PPV & 88 & 18.2 [14.8-21.6] & $4.0[3.2-4.8]$ \\
\hline SVV & 88 & $18.2[14.8-21.6]$ & $4.0[3.2-4.8]$ \\
\hline $\mathrm{PPV}+\mathrm{SVV}$ & 24 & $5.0[3.1-6.9]$ & $1.1[0.7-1.5]$ \\
\hline PLR & 238 & $49.3[44.8-53.8]$ & $10.7[9.4-12.0]$ \\
\hline Echo variables & 45 & $9.3[6.7-11.9]$ & $2.0[1.4-2.6]$ \\
\hline
\end{tabular}

$\mathrm{SvO}_{2}$ mixed venous oxygen saturation, $\mathrm{Scv} \mathrm{O}_{2}$ central venous oxygen saturation, $S V V$ stroke volume variation, $P P V$ pulse pressure variation, $C V P$ central venous pressure, $P A O P$ pulmonary artery

impairment [20] and that improving MAP and diuresis is not sufficient for improving patient outcome [21-23].

These findings are in line with the ones published by Boulain and coauthors [24]. In their study, limited to ICUs in France, low blood pressure and low urine output were the most used triggers for fluid administration. The wider scope of our study demonstrates that this is common practice around the globe. It is interesting that so much attention is paid to the blood pressure at the bedside. This variable is the most used both for triggering and assessing the response to an FC. It is possible that the goal occlusion pressure, GEDVI global end diastolic volume, PLR passive leg raising, Echo echocardiography

of many clinicians is the one of increasing BP with an FC. On the other hand it is possible that arterial blood pressure was used as a surrogate of cardiac output (CO). This seems common practice despite the known limitations of this variable when used to estimate $\mathrm{CO}$. The increase in arterial pressure during an FC for instance is variable and depends on vascular tone and arterial elastance [25]. In patients increasing their $\mathrm{CO}$ in response to fluids, arterial blood pressure increases only in those with high arterial elastance [26, 27]. In summary, while fluids are mostly indicated to increase cardiac output $[11,17,18]$ and tissue 
Fig. 1 Further fluid administration post fluid challenge
Fluid administration post fluid challenge

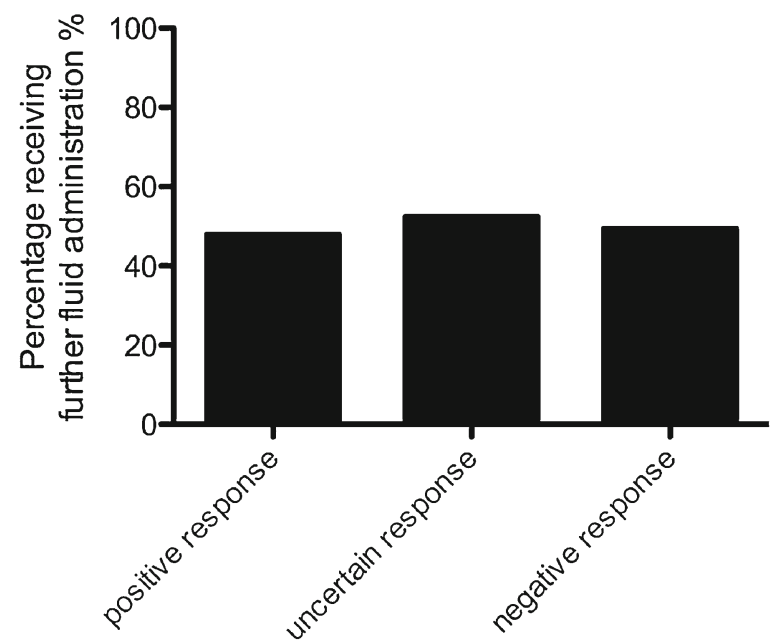

\begin{tabular}{|l|ll|}
\hline Further fluid administration $-\mathrm{n}(\%)$ & $1050(47.4 \pm 2.5)$ & \\
\hline with an initial positive response $\mathrm{n}(\%)$ OR & $739(47.9 \pm 2.5)$ & Ref \\
\hline with an initial negative response $\mathrm{n}(\%)$ OR & $212(49.4 \pm 6.6)$ & OR $0.94(0.76-1.16)$ \\
\hline with an initial uncertain response n (\%) OR & $99(52.4 \pm 7.1)$ & OR 0.83 (0.62-1.13) \\
\hline
\end{tabular}

perfusion [19] and not to just to increase blood pressure, at the bedside clinicians rely heavily on this variable both to predict and assess fluid responsiveness (Table 4).

Importantly, in almost half of the patients no hemodynamic variable was used to predict fluid responsiveness - and if used CVP was used most often. This is interesting considering that the CVP is a poor variable to predict fluid responsiveness $[12,14,28]$.

The use of dynamic indices of preload was infrequent in our study. Cyclical changes in stroke volume (stroke volume variation, SVV) and pulse pressure (pulse pressure variation, PPV) during mechanical ventilation have been shown to predict fluid responsiveness with high sensitivity and specificity [29]. However, one of the limitations is that the patient has to be in controlled ventilation with tidal volumes equal to or higher than $8 \mathrm{ml} / \mathrm{kg}$ of ideal body weight [30], and with no arrhythmias. It is possible that the limited use of these three dynamic indices (in total $9 \%$ of patients) was influenced by a high prevalence of patients with preserved spontaneous breathing activity. Another possible explanation is that we encouraged investigators to look at the first fluid challenge in our study. In this case flow monitors may have not have been in place yet. In this scenario though, we would have expected a more prevalent use of echocardiography. Of note, this was used to indicate FC in only $2 \%$ of the patients.

Passive leg rising is a maneuver that produces an autologous fluid challenge by shifting venous blood from the legs to the intrathoracic compartment. The response measured by a flow monitor is able to predict the response to a fluid challenge. This has been studied and validated with different flow monitors. With a lower degree of accuracy with respect to cardiac output and stroke volume, blood pressure monitoring could be used for this technique, too [31]. Considering that an increase in blood pressure was used as the positive indicator of a fluid challenge in two-thirds of the cases, our data suggest that arterial pressure is the hemodynamic variable on which the majority of clinicians focus. Hypotension and weaning of vasopressor were the main indications to give an FC and the response in arterial pressure was the most used one for evaluation of possible benefit.

Our findings highlight a possible safety problem. Half of the patients with a negative response received further fluids. Of note, in three out four cases no safety limits were used at all. While CVP is a poor marker of preload and fluid responsiveness, it is one of the regulating functions of the venous return and a raise in CVP may be used as a safety limit $[9,32-34]$. Given this finding and that patients received further fluids despite no response to the initial FC, the current practice and evaluation of FC and fluid administration in critically ill patients seems to be arbitrary, not evidence-based and possibly harmful.

We also found a high variability in the type of fluid used with higher use of crystalloids compared to colloids. It is difficult to interpret these results, since this study was performed during a time of high debate among intensive care clinicians following the publication of large 
Table 4 Judged response to fluid challenge

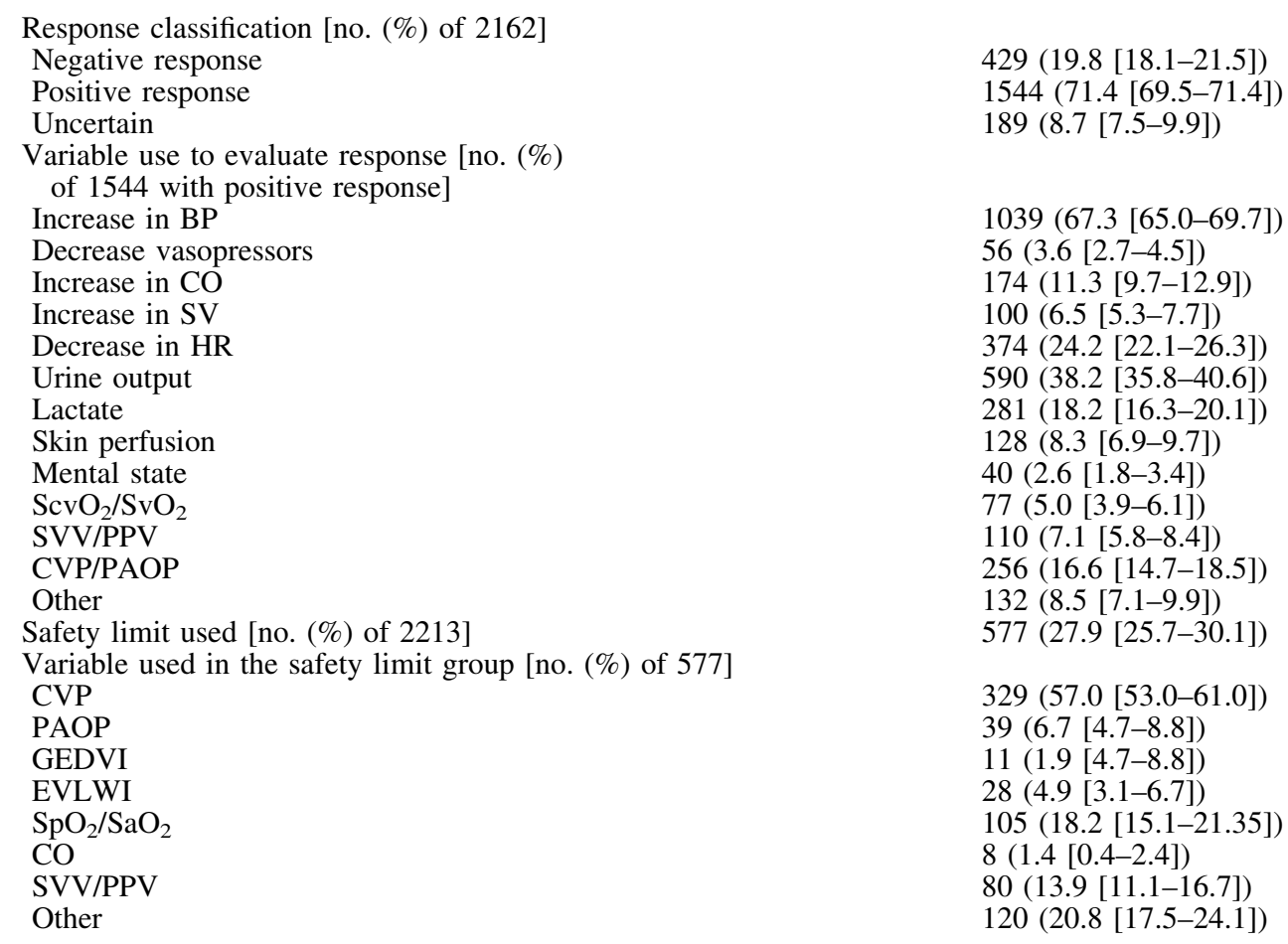

$\mathrm{BP}$ blood pressure, $\mathrm{CO}$ cardiac output, $\mathrm{SV}$ stroke volume, $\mathrm{HR}$ heart rate, $\mathrm{Sv} \mathrm{O}_{2}$ mixed venous oxygen saturation, $\mathrm{ScvO}_{2}$ central venous oxygen saturation, $S V V$ stroke volume variation, $P P V$ pulse pressure variation, $C V P$ central venous pressure, $P A O P$ pulmonary artery occlusion pressure, GEDVI global end diastolic volume, EVLWI extravascular lung water index randomized controlled trials advocating the use of crystalloids versus colloids [1, 35-38].

Our study has some obvious strengths. First, to the best of our knowledge this study is the largest prospective observational study investigating FCs in critically ill patients and thus provides a reasonably exact estimate of the current practice of the FCs given. Second, the international multicenter design limiting the cases from individual sites increases its external validity. However, there are several limitations of our study to be considered. First, we recorded only when FCs were given and not when FCs were not given. Thus, in practice we may have underestimated the times when variables used to predict fluid responsiveness were used. Second, we encouraged investigators to record data on the first fluid challenge, which may have several implications. At early stages, a positive response to fluids is more likely and patients are often less invasively monitored. Studying patients at later stages may have yielded different results. Third, we allowed a wide range of options (volume, type of fluid, first or subsequent FC) to be recorded during an FC. It is possible that some investigators considered an FC what would be normally defined a more sustained volume expansion.
We conclude that the current practice and evaluation of FC in critically ill patients seems to be arbitrary. While not demonstrable in this observational study, this practice does not seem evidence-based and could be harmful.

Our findings highlight an urgent need for more educational activities and more research to assess whether a more standardized approach to a fluid challenge could lead to better patient-centered outcomes.

Conflicts of interest Antonio Artigas is a scientific advisor of B. Braun and Ferrer, received a restricted research grant from Grifols and Pulsion, and is an invited speaker of Grifols. Michael Sander received financial support from Masimo, Pulsion, Edwards Lifesciences, and Maquet. Jean-Louis Teboul is a member of the medical advisory board of Pulsion. The other authors declare no conflict of interest.

Open Access This article is distributed under the terms of the Creative Commons Attribution-NonCommercial 4.0 International License (http://creativecommons.org/licenses/by-nc/4.0/), which permits any noncommercial use, distribution, and reproduction in any medium, provided you give appropriate credit to the original author(s) and the source, provide a link to the Creative Commons license, and indicate if changes were made. 


\section{References}

1. Myburgh JA, Mythen MG (2013) Resuscitation fluids. N Engl J Med 369:2462-2463

2. Hamilton MA, Cecconi M, Rhodes A (2011) A systematic review and metaanalysis on the use of preemptive hemodynamic intervention to improve postoperative outcomes in moderate and high-risk surgical patients. Anesth Analg 112:1392-1402

3. Cecconi M, Corredor C, Arulkumaran N, Abuella G, Ball J, Grounds RM, Hamilton M, Rhodes A (2013) Clinical review: goal-directed therapy-what is the evidence in surgical patients? The effect on different risk groups. Crit Care 17:209

4. Cecconi M, De Backer D, Antonelli M, Beale R, Bakker J, Hofer C, Jaeschke R, Mebazaa A, Pinsky MR, Teboul JL, Vincent JL, Rhodes A (2014) Consensus on circulatory shock and hemodynamic monitoring. Task force of the European Society of Intensive Care Medicine. Intensive Care Med 40:1795-1815

5. Lee SJ, Ramar K, Park JG, Gajic O, Li G, Kashyap R (2014) Increased fluid administration in the first three hours of sepsis resuscitation is associated with reduced mortality: a retrospective cohort study. Chest 146:908-915

6. Payen D, de Pont AC, Sakr Y, Spies C, Reinhart K, Vincent JL, Sepsis Occurrence In Acutely Ill Patients (SOAP) Investigators (2008) A positive fluid balance is associated with a worse outcome in patients with acute renal failure. Crit Care 12:R74

7. Vaara ST, Korhonen AM, Kaukonen KM, Nisula S, Inkinen O, Hoppu S, Laurila JJ, Mildh L, Reinikainen M, Lund V, Parviainen I, Pettila V, Group FS (2012) Fluid overload is associated with an increased risk for 90-day mortality in critically ill patients with renal replacement therapy: data from the prospective FINNAKI study. Crit Care 16:R197

8. National Heart L, Blood Institute Acute Respiratory Distress Syndrome Clinical Trials N, Wiedemann HP, Wheeler AP, Bernard GR, Thompson BT, Hayden D, deBoisblanc B, Connors AF Jr, Hite RD, Harabin AL (2006) Comparison of two fluid-management strategies in acute lung injury. N Engl J Med 354:2564-2575

9. Weil MH, Henning RJ (1979) New concepts in the diagnosis and fluid treatment of circulatory shock. Thirteenth annual Becton, Dickinson and Company Oscar Schwidetsky Memorial Lecture. Anesth Analg $58: 124-132$
10. Vincent JL, Weil MH (2006) Fluid challenge revisited. Crit Care Med 34:1333-1337

11. Cecconi M, Parsons AK, Rhodes A (2011) What is a fluid challenge? Curr Opin Crit Care 17:290-295

12. Marik PE, Baram M, Vahid B (2008) Does central venous pressure predict fluid responsiveness? A systematic review of the literature and the tale of seven mares. Chest 134:172-178

13. Marik PE, Cavallazzi R, Vasu T, Hirani A (2009) Dynamic changes in arterial waveform derived variables and fluid responsiveness in mechanically ventilated patients: a systematic review of the literature. Crit Care Med 37:2642-2647

14. Marik PE, Cavallazzi R (2013) Does the central venous pressure predict fluid responsiveness? An updated metaanalysis and a plea for some common sense. Crit Care Med 41:1774-1781

15. Dellinger RP, Levy MM, Rhodes A, Annane D, Gerlach H, Opal SM, Sevransky JE, Sprung CL, Douglas IS, Jaeschke R, Osborn TM, Nunnally ME, Townsend SR, Reinhart K, Kleinpell RM, Angus DC, Deutschman CS, Machado FR, Rubenfeld GD, Webb S, Beale RJ, Vincent JL, Moreno R, Surviving Sepsis Campaign Guidelines Committee including The Pediatric Subgroup (2013) Surviving Sepsis Campaign: international guidelines for management of severe sepsis and septic shock, 2012. Intensive Care Med 39:165-228

16. Knott A, Pathak S, McGrath JS, Kennedy R, Horgan A, Mythen M, Carter F, Francis NK (2012) Consensus views on implementation and measurement of enhanced recovery after surgery in England: Delphi study. BMJ Open. doi: 10.1136/bmjopen-2012-001878

17. Silva E, De Backer D, Creteur J, Vincent JL (2004) Effects of fluid challenge on gastric mucosal PCO2 in septic patients. Intensive Care Med 30:423-429

18. Cecconi M, Reynolds TE, Al-Subaie N, Rhodes A (2007) Haemodynamic monitoring in acute heart failure. Heart Fail Rev 12:105-111

19. Ospina-Tascon G, Neves AP, Occhipinti G, Donadello K, Buchele G, Simion D, Chierego ML, Silva TO, Fonseca A, Vincent JL, De Backer D (2010) Effects of fluids on microvascular perfusion in patients with severe sepsis. Intensive Care Med 36:949-955
20. Sakr Y, Dubois MJ, De Backer D, Creteur J, Vincent JL (2004) Persistent microcirculatory alterations are associated with organ failure and death in patients with septic shock. Crit Care Med 32:1825-1831

21. Rivers E, Nguyen B, Havstad S, Ressler J, Muzzin A, Knoblich B, Peterson E, Tomlanovich M (2001) Early goaldirected therapy in the treatment of severe sepsis and septic shock. N Engl J Med 345:1368-1377

22. Jansen TC, van Bommel J, Schoonderbeek FJ, Sleeswijk Visser SJ, van der Klooster JM, Lima AP, Willemsen SP, Bakker J (2010) Early lactate-guided therapy in intensive care unit patients: a multicenter, open-label, randomized controlled trial. Am J Respir Crit Care Med 182:752-761

23. Jones AE, Shapiro NI, Trzeciak S, Arnold RC, Claremont HA, Kline JA, Emergency Medicine Shock Research Network I (2010) Lactate clearance vs central venous oxygen saturation as goals of early sepsis therapy: a randomized clinical trial. JAMA 303:739-746

24. Boulain T, Boisrame-Helms J, Ehrmann S, Lascarrou JB, Bougle A, Chiche A, Lakhal K, Gaudry S, Perbet S, Desachy A, Cabasson S, Geneau I, Courouble P, Clavieras N, Massanet PL, Bellec F, Falquet Y, Reminiac F, Vignon P, Dequin PF, Meziani F (2015) Volume expansion in the first 4 days of shock: a prospective multicentre study in 19 French intensive care units. Intensive Care Med 41:248-256

25. Pierrakos C, Velissaris D, Scolletta S, Heenen S, De Backer D, Vincent JL (2012) Can changes in arterial pressure be used to detect changes in cardiac index during fluid challenge in patients with septic shock? Intensive Care Med 38:422-428

26. Cecconi M, Monge Garcia MI, Gracia Romero M, Mellinghoff J, Caliandro F, Grounds RM, Rhodes A (2014) The use of pulse pressure variation and stroke volume variation in spontaneously breathing patients to assess dynamic arterial elastance and to predict arterial pressure response to fluid administration. Anesth Analg 120:76-84

27. Monge Garcia MI, Gil Cano A, Gracia Romero M (2011) Dynamic arterial elastance to predict arterial pressure response to volume loading in preloaddependent patients. Crit Care 15:R15

28. Cecconi M, Aya HD (2014) Central venous pressure cannot predict fluidresponsiveness. Evid Based Med 19:63 
29. Monnet X, Teboul JL (2013) Assessment of volume responsiveness during mechanical ventilation: recent advances. Crit Care 17:217

30. De Backer D, Heenen S, Piagnerelli M, Koch M, Vincent JL (2005) Pulse pressure variations to predict fluid responsiveness: influence of tidal volume. Intensive Care Med 31:517-523

31. Monnet X, Rienzo M, Osman D, Anguel N, Richard C, Pinsky MR, Teboul JL (2006) Passive leg raising predicts fluid responsiveness in the critically ill. Crit Care Med 34:1402-1407

32. Cecconi M, Aya HD, Geisen M, Ebm C, Fletcher N, Grounds RM, Rhodes A (2013) Changes in the mean systemic filling pressure during a fluid challenge in postsurgical intensive care patients. Intensive Care Med 39:1299-1305
33. Guyton AC, Richardson TQ, Langston JB (1964) Regulation of cardiac output and venous return. Clin Anesth 3:1-34

34. Berlin DA, Bakker J (2014)

Understanding venous return. Intensive Care Med 40:1564-1566

35. Gattas DJ, Dan A, Myburgh J, Billot L, Lo S, Finfer S (2013) Fluid resuscitation with $6 \%$ hydroxyethyl starch (130/0.4 and 130/0.42) in acutely ill patients: systematic review of effects on mortality and treatment with renal replacement therapy. Intensive Care Med 39:558-568

36. Myburgh JA, Finfer S, Bellomo R, Billot L, Cass A, Gattas D, Glass P, Lipman J, Liu B, McArthur C, McGuinness S, Rajbhandari D, Taylor CB, Webb SA (2012) Hydroxyethyl starch or saline for fluid resuscitation in intensive care. N Engl J Med 367:1901-1911
37. Perner A, Haase N, Guttormsen AB, Tenhunen J, Klemenzson G, Aneman A, Madsen KR, Moller MH, Elkjaer JM, Poulsen LM, Bendtsen A, Winding R, Steensen M, Berezowicz P, SoeJensen P, Bestle M, Strand K, Wiis J, White JO, Thornberg KJ, Quist L, Nielsen J, Andersen LH, Holst LB, Thormar K, Kjaeldgaard AL, Fabritius ML, Mondrup F, Pott FC, Moller TP, Winkel P, Wetterslev J (2012) Hydroxyethyl starch 130/0.42 versus Ringer's acetate in severe sepsis. N Engl J Med 367:124-134

38. Reinhart K, Perner A, Sprung CL, Jaeschke R, Schortgen F, Johan Groeneveld AB, Beale R, Hartog CS (2012) Consensus statement of the ESICM task force on colloid volume therapy in critically ill patients. Intensive Care Med 38:368-383 